el perro Cipión comenta: "Celadores prudentísimos tiene nuestra república que, considerando que España cría y tiene en su seno tantas víboras como moriscos, ayudados de Dios hallarán a tanto daño cierta, pronta y segura salida".

De no existir otros datos para fechar el Coloquio, ¿no bastaría éste? ¿Puede hablarse aquí de cualquier artilugio literario? ¿Cómo podría defenderse la idea de que el escritor simula que el destierro no ha ocurrido? Defender esta idea sería, a nuestro juicio, lo mismo que defenderla en el Persiles. La rotundidad de ambos pasajes es inconmovible, como lo es la del Quijote en sentido contrario. Estos tres textos nos están hablando à voces.

RAFAel OSUna

Middlebury College.

\title{
ADICIONES A LAS CITAS POÉTICAS DE CALDERÓN
}

Al reunir las canciones y citas poéticas incorporadas por Calderón de la Barca en sus obras dramáticas, E. M. Wilson y J. SAGE ${ }^{1}$ han prestado un valioso servicio, lo mismo a los estudios calderonianos que a las investigaciones en torno a la poesía de la época. Para ese minucioso y cuidado trabajo de erudición los autores entresacaron de las piezas teatrales cuanto parecía ser recuerdo deliberado -textual o no, parcial o completo- de composiciones de otros autores y de cantares anónimos populares. El resultado - 185 textos- nos muestra a un Calderón muy aficionado a halagar la memoria literaria de su público y complacerlo con canciones conocidas de todos. Nos lo revela además como admirador de Lope, Cervantes, Antonio de Mendoza, Salinas y, muy particularmente, Góngora.

Porque Wilson y Sage, siguiendo con amorosa paciencia el rastro de esos textos, logran identificar a los autores de muchos de ellos'; también reúnen abundantes paralelos contemporáneos. Es notable, por ejemplo, la riqueza con que documentan canciones como "Arded, corazón, arded" (núm. 17), "De los desdenes de Gila" (50), "...mirad con quién y sin quién..." (103), "Tú, que me miras a mi" (163), y tópicos como "Dígasme tú..." (54), "yo te conocí edificio..." (78), las "eses" de los enamorados (44). Ya sabemos que las búsquedas de este tipo no acaban nunca, y los hallazgos tampoco. Es una labor que necesariamente tiene que ser colectiva: cada investigador añadirá su grano de arena, contribuyendo de paso a ese gran catálogo de la poesía del Siglo de Oro que todos estamos añorando y que algún día tendrá que hacerse. Van, pues, aquí algunos datos más: en primer lugar, unos cuantos cantares y citas que aparecen en obras de Calderón o atribuidas

1 Poesias liricas en las obras dramáticas de Calderón. Citas y glosas, Tamesis, London, 1964; xix +165 pp.

2 "Estudio curioso y no fácil de llevar a término sería el de averiguar el origen de la multitud de canciones que intercaló en sus dramas el autor de La vida es stueño...", decía ya en 1909 León Medina (cf. nota siguiente). 
a él y que no figuran en el libro de Wilson-Sage; en segundo, adiciones a su documentación de ciertos textos ${ }^{3}$.

(I)

A la viña, a la viña, zagales!

:Zagales, venid, venid a la viña!

iA la viña, a la viña, zagales!

¡Y vaya de gyra, de bulla y de bayle!

Auto La viña del Señor, ed. Pando, t, 4, pp. $185 s$ (ed. Valbuena, t. 3, pp. $1486 a, 1487 a$ ).

Probable recreación de un cantar de viñadores. Cf. "iA la viña, viñadores, / a la viña divinal!", farsa sacramental La entrada del vino (RovANET, Colección, t. 3, p. 491); “'A la viña, viñadores, / que sus frutos amores son!", LOPE DE VEGA, El heredero del cielo (Acad, t. 2, p. 184); "A la viña, señores, al bochorno, / que el fruto es mucho, y los obreros pocos", MIRA DE MEscuA, Auto del heredero (Autos sacramentales, Madrid, 1655, f. 215v; Autos sacramentales y al nacimiento, Madrid, 1675 , p. 134).

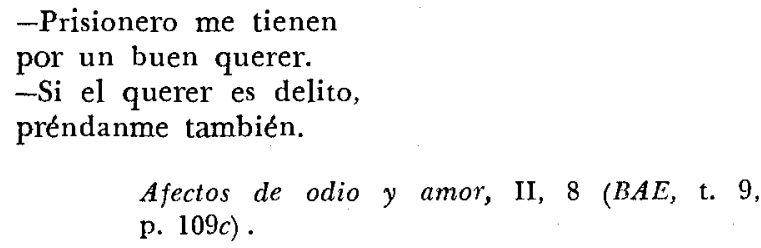

Probablemente se hallaba bastante difundida. Ya en 1616 aparece vuelta a lo divino en la Minerva sacra de Miguel Toledano (ed. de Madrid, 1949, p. 62) : "Preso está mi Niño / por quererme bien. / Si el querer es delito, / préndanme con él”.

3 Para las referencias bibliográficas utilizo las mismas abreviaturas de Wilso: y Sage, y además las siguientes:

Andrade Caminha, Poesias inéditas: ed. J. Priebsch, Halle, 1898.

Cancionero classense: A. REstoRI, "II Cancionero classense 263", Rendiconti della R. Accad. dei Lincei, Cl. di Scienze Morali.., 5? Serie, 11 (1902), 99-136.

Cancionero sevillano: H. S. A., ms. B2486. Cf. M. Frenk Alatorre, "EI cancionero sevillano de la Hispanic Society (ca. 1568)", NRFH, 16 (1962), 355-394.

Correas: Gonzalo Correas, Vocabulario de refranes y frases proverbiales (1627). ed. L. Combet, Bordeaux, 1967.

Medina: León Medina, "Frases literarias afortunadas", $R H i, 18$ (1908), 162-232; 20 (1909), 211-297; 23 (1910), 188-234; 25 (1911), 47-113 [doy en cada caso año y página]. Este trabajo hubiera interesado a Wilson y Sage; contiene, entre otras, referencias a sus núms. 95 (1908, pp. 199-201) y 166 (1908, pp. 212-214).

Valdivielso, Doze actos: Joseph de VAldivizso, Doze actos sacramentales y dos comedias divinas, Toledo, 1622. 
(III)

Pues soy para dama más lo que para esposa menos

El médico de su honra, I, 7 (BAE, t. 7, p. 349a).

Que soy grande para dama, y para esposa soy chica.

No hay burlas con el amor, II, 10 (BAE, t. 9, p. $317 c)$.

Tópico frecuente en el teatro de la época. Cf. Ruiz de Alarcón, Las paredes oyen, III, 2 (Obras completas, ed. A. Millares Cario, t. 2, México, 1957, p. 271) : "grande para dama soy, / si pequeña para esposa"; Los pechos privilegiados, I, 7: "que si con tal sangre y fama / para esposa me juzgó / pequeña, me tengo yo / por grande para su dama" (ed. cit., t. 2, 1959, p. 674); Trigueros, Sancho Ortiz de las Roelas (refundición de La Estrella de Sevilla): "Soy (dijo a mi furor loco) / para esposa vuestra poco, / para dama vuestra mucho". Cf. Medina, 1911, pp. 100-101.

Vaya el mezquino, vaya, que no lleva forma de dar una blanca.

Loa al auto El veneno y la triaca, ed. Pando, t. 4 , p. 206 (después de "Den para la maya...", WrisonSAGE, nứm. 51).

Recreación de "Pase (pase) el pelado, / que no lleva blanca ni cornado", con que se escarnecia a los que no daban para la maya: Baile de la maya (Cotarelo, Entremeses, t. 2, p. 485a); Lope de VegA, auto La maya (Acad, t. 2, p. 51a) y El laberinto de Creta, III (Acad, t. 6, p. 138b) ; Valdivielso, auto El hijo pródigo (Doze actos, f. 120v); Correas, p. 465b: "Pelón, pelado, ke no tiene blanka ni kornado". Cf. A. González Palencia y E. Mele, La maya, Madrid, 1944, passim.

(V)

Venga norabuena,
norabuena venga.

Psiquis y Cupido, ed. Apontes, t. 1, p. 58 (ed. Valbuena, t. 3, p. 354a); La primer flor del Carmelo, ibid., p. 150 (ibid., p. $638 a)$.

Es una de las fórmulas más frecuentes en las canciones de bienvenida de la época. Cl. "Venga norabuena / la Paloma bella (o: nuesamo a su tierra, Cupido a nuestras selvas), / norabuena venga", Lope DE VEGA, Pastores de Belén, II (Madrid, 1612, f. 85v); Los Guzmanes de Toral, I (AcadN, t. 11, pp. 76 y 9a); Cervantes, La casa de los celos, II (ed. Schevill-Bonilla, t. 1, p. 190). 
Assentéme no formigueyro:

¡docho a demo [o] assentadeyro!

Entremés de las lenguas, atribuido a Calderón en Entremeses varios aora nuevamente recogidos, Zaragoza, herederos de Diego Dormer, s. a. (ejemplar en la B. N. P.) .

Figura en Mari-Hernández la gallega, II, 4 de Tirso (ed. Ríos, t. 2, p. 83a) ; en el Baile del Sotillo de Manzanares (Cotarelo, Entremeses, t. 2, p. 481 $b$; siguen ahí dos versos paralelos). Cf. Correas, p. 275a: "Sentéme en un hormiguero, / ¡o, ké mal asentadero!"

Dilín, dilín;

pues ves que tocan a San Antón, dilón, dilón.

Entremés de la rabia, Primera parte, atribuido a Calderón en B. N. M., ms. 15,596.

Cf. "Dilín, dilín, / dilón, dilón. / ¡Ay, que tañen en San Martín! / ¡Ay, que tocan en San Antón!", LOPE DE VEGA, No son todos ruiseñores, III (Acad, t. 15, p. 115b); "Toquen y tañan las campanillas: / dilín, dilín, / media capa es de San Martín; / dilín, dilón, / y el cochino, de San Antón...", QuiÑones de BENAVENTE (?), Entremés de los gorrones (Cotarelo, Entremeses, t. 2, p. 766b).

Núm. 17. "Arded, coraçón, arded, / que yo no os puedo valer" está también en otra obra atribuida a CALDERón: El escándalo de Grecia contra las sacras imágenes, II (Comedias nuevas escogidas, Parte $11, \mathrm{f}$. 165v). En esa misma forma aparece el cantar en GómEz TEJADA DE Los Reyes, Noche Buena. Autos..., Madrid, 1661, p. 327; en Pérez de MoNTALvÁ, No hay vida como la honra, II (BAE, t. 45, p. 486a); en FraNCisco de Portugal, Divinos e humanos versos, Lisboa, 1652, p. 63. En las Obras del mismo autor, Lisboa, 1683, p. 10, aparece nuevamente, con glosa distinta; esta vez el tex to reza: "Arder... / que no os puedo valer". También comienzan con "Arder..." el texto de British Museum, ms. Add. 10,328 , f. $265 \mathrm{r}$; la versión portuguesa glosada por ANDRAde CAminha, Poesias inéditas, núm. 8, por Bernardes, Rimas varias, Lisboa, 1597, f. 134v, y por FerReira de VAsconcellos, Ulysippo, Lisboa, 1618, fs. 256v s., y la recreación de Lucas Fernández en su Farsa o cuasi comedia, ed. Acad., p. 59: "Arder, corazón, arder, / sin fenescer ni acabar / ni cesar: / que no vos puedo valer". Todavía Sor JUANa INÉs DE LA $\mathrm{C}_{\mathrm{RUZ}}$ se interesa por el antiguo cantarcillo, el cual remodela así: "Arded, corazón, arded, / pues quisistes padecer" (Obras completas, t. 2, México, 1952, p. 278). La canción, como se ve, era de las más divulgadas 
(14 testimonios citan Wilson y Sage, y aquí aduzco otros 12) y pudo así adquirir carácter proverbial, como cuando Antolínez de Piedrahita (Carnestolendas de Zaragoza, Zaragoza, 1661, p. 59) dice que "El Conde de Villamediana estava después... tan desconsolado como Arded, coraçón, arded..."

Núm. 19. "Ay, cómo gime, mas ay, cómo suena...": otras adaptaciones en CÁNCER, Entremés del Libro de qué quieres, boca (Autos sacramentales.... Madrid, 1675, p. 233); Quiñones de Benavente, entremés cantado El licenciado y el bachiller (Cotarelo, Entreseses, t. 2, p. 539); TEJADA DE Los REYes, auto El soldado (Noche buena..., Madrid, 1661, pp. 180-181).

Núm. 27. "Canario a bona, / arrofaifá...": LoPE DE VEGA incorpora el baile de Canaria bona en su auto La Araucana (Acad, t. 3, p. 114b): "Canaria bona, / lirunfá, / que Rengo es vencido / por Caupolicán"; y en San Diego de Alcalá, II (Acad, t. 5, pp. 50-51): "Canaria lira, / lilirumfá, / que todo lo vence / amar y callar". El verso "Urruá, urruá, que en la venta está" es estribillo de la jácara de Quevedo "Ya se salen de Alcalá" (ed. Astrana Marín, p. 218) ; y cf. El entretenido, la dueña y el soplón (BAE, t. 23, p. 371a): "¿Qué quiere decir «Hurruá, que en la venta (na) está »?" Cf. además Villaviciosa, Bayle de los sones (Tardes apacibles de gustoso entretenimiento..., Madrid, 1663, f. 135v): "(Sale el Canario de vegete, dando). Veg.: Alcalde, amigo, rufayfá. Música: Si su padre lo sabe, matarte ha". (Padre, y no madre, se lee también en CEJAdor, I, 484).

Núm. 30. Para "Pajarito que vas a la fuente...", cf. Lope de Vega, Lo que pasa en una tarde, 1 (AcadN, t. 2, p. 293b): "-El pájaro que se vio / solo, del nido voló... / $-\Varangle$ No ha sido el que fue a la fuente...? / ¿no le dijo "Bebe y venten?" Al propio Lope se atribuye en el Cartapacio de Pedro de Penagos (1593- ), fol. 123v, esta recreación: "Moçuela del botín verde, / que me mata de amor, cúbrelo y bete..."

Núm. 38. "En el campo me metí..." La cuarteta, tal como la trae Castillejo, fue glosada también por Pedro de Padilla (cf. H. Janner, La glosa en el Siglo de Oro, Madrid, 1946, pp. 42-43). Fray Antonio DE Guevara, Epistolas familiares, II, 25 (ed. J. M. de Cossío, t. 2, Madrid, 1952, p. 301) la cita como del Marqués de Santillana y en esta forma: "En la guerra que poseo, / siendo mi ser contra sí, / pues yo mismo me guerreo, / defiéndame Dios de mí". El verso "comigo mismo guerreo" está en una glosa de Rodrigo Dávalos (Cancionero general, ed. Bibliófilos, núm. 176); cf. "vencido como me veo / en esta fuerte pelea / que yo comigo peleo", de Jorge Manrique (ibid., núm. 191) . Cf. Medina, 1911, pp. 50-51.

Núm. 42. "Cuando entráredes, caballero..." se glosa también en el Cancionero sevillano, fs. $249 \mathrm{v}$ s., y en Andrade Caminha, Poesias inéditas, núm. 440.

Núm. 67. "Entra mayo y sale abril..." figura además en Correas, p. $139 b$ ("kuán floridito" o "ké florido") y en La peña de Francia, III,

4 En cuanto a la última referencia de WiLSON-SAGE: la música del cancionero ms. M 454 de la Bibl. Central de Barcelona (f. 180 -no 170- bis) lleva la letra "Paxarico, que vas a la fuente, / beb'ora y vente". 
1, de Trrso (ed. Ríos, t. 1, p. 1764a: "cuán garridico"). Lope cita el primer verso en El despertar a quien duerme, I (AcadN, t. 11, p. 717a).

Núm. 72. "Por el montecico sola..." La versión del Romancero de la Brancacciana (que es la misma de Ramillete, VI, Flor, VI y R.G.) está también en B.N.M., ms. 17,557, fs. $66 \mathrm{v}$ y 68 ; con variantes, en British Museum, ms. Add. 18,706, f. 70. La otra versión (con "que me fatigaba la sed") figura además en la ensalada "La caza" de Mateo Flecha, Bibl. Central de Barcelona, ms. M. 588/2, Tiple, f. 50, y en una ensalada anónima de la B.N.M., ms. 17,698 (el "Cancionero toledano", cuya edición preparan Alberto Blecua y Rosa María Falgueras), f. 6v. Cf. "Por el montecico sola, / sola por el monte", Aqui comienza vna muy graciosa ensalada para la noche de Nauidad... por Fernando Diaz de Montoya, Sevilla, 1603 (H.S.A.), f. [2], y, con variantes, en el Libro de la vida y costumbres de don Alonso Enriquez de Guzmán, ed. H. Keniston, $B A E$, t. 126 , p. $82 a$.

Núm. 81 A. "Esta noche me cupo la posta...": los versos 1-3 parecen parodia de "Esta noche me cabe la vela, / ruego yo a mi Dios que no me duerma", Correas, p. 150b; M. Toledano, Minerva sacra, op. cit., p. 22; con variantes en el Romancero de Barcelona, núm. 37 ("me cupo"); con dos versos más en Valdivielso, auto El Fénix de amor (Doze actos, f. 37).

Núm. 87 A. "Hallarás quien bien te quiera..." La cita, en Calderón y Quiñones de Benavente, constituye el final de una cuarteta que debe de haber circulado bastante. Conozco una versión profana: "Bien sé, Gila, que a doquiera / quien te quiera hallarás: / bien hallarás quien te quiera, / mas no quien te quiera más", B.N.M., ms. 4072 (apud Gallardo, t. 3, col. 1138, y Cejador, t. 4, núm. 2312); y una versión a lo divino: "Alma, bien sé que hallarás / quien te quiera y te requiera; / hallarás quien bien te quiera, / mas no quien te quiera más", Valdivielso, auto El Fénix de amor (Doze actos, f. 39). Cf. YveTTE JIMÉNEZ DE BÁEz, Lírica cortesana y lírica popular actual, El Colegio de México, México, 1969, pp. 18-19.

Núm. 90. "La gala de Venus viva..." Los paralelos pueden multiplicarse. Cf. por ejemplo "Viva la gala y viva el amor, / y viva la causa del vencedor", JuAn Antonio Calderón, en Flores de poetas ilustres de España, Segunda parte, Sevilla, 1896, p. 284; "Vívame la gala / de la Paridera, / que ha parido un Niño / quedando doncella", JUAN Bautista de Villegas, El Sol a media noche y estrellas a medio dia, III (Comedias nuevas escogidas, t. 7, f. 105), etc.

Núm. 97. "Madre, la mi madre, / guardas me ponéis..." Los versos "que si yo no me guardo, / mal me guardaréis" se citan en la Loa con que empezó Escamilla en Madrid, atribuida a Calderón en B.N.M., ms. 14,856, f. 21. La letra completa está también en el Arte de galanteria de Francisco de Portugal, Lisboa, 1670, p. 125, y, con la glosa de $L a$ entretenida, en el ms. 12,956 ${ }^{49}$ de la B.N.M. (siglo xvinr).

Núm. 101. "Mañanicas floridas / de abril y mayo..." La seguidilla figura, con otras muchas, en un romancerillo valenciano de 1597, conservado en Pisa (RHi, 65, 1925, pp. 153-263, núm. 52) y en Munich (Los cancionerillos de Munich..., ed. A. Rodríguez-Moñino, Madrid, 
1963, núm. 151); aparece glosada en el Romancero de Barcelona, núm. 125, y como estribillo de un romance en El acero de Madrid, I, de Lope (AcadN, t. 11, p. 178b). Según Medins, 1909, p. 287, Calderón tomó de Lope esta canción, que, por cierto, sobrevive textualmente en Albarracín (cf. González Palencia-Mele, La maya, op. cit., p. 131).

Núm. 103. "Sin vos y con mi cuidado..." Fue glosado además por Gregorio Silvestre (Las obras, Lisboa, 1592, fs. $111 \mathrm{v}$ s.; también en el Cancionero sevillano, f. 70v) y por López Maldonado (Cancionero, Madrid, 1586; ed. facs., Madrid, 1932, fs. 29v s.) e intercalado por PADIlla en la "Ensaladilla III" de su Romancero. En versión portuguesa, y sin el tercer verso, lo glosaron Camões (Rimas, Coimbra, 1953, pp. 50 y 51), Andrade Caminha (Poesias inéditas, núm. 374) y BerNARDES (Rimas varias, op. cit., f. 139v). La versión "Con amor y sin dinero, / mirá con quién y sin quién..." aparece, como "vilancete velho", glosada dos veces en ANDrade Caminha (op. cit., núms. 451 y 452). Conozco otras dos "divinizaciones", además de la de López de Úbeda: "Sin Dios y con mi pecado, / mirad con quién y sin quién / para que me vaya bien", en un ms. salmantino del siglo xvi (Anales salmantinos, 2, 1929, p. 308) y "Tengo amor sin esperanza: / mirad...", en Alonso de Ledesma, Segunda parte de los conceptos espirituales, Barcelona, J. Cendrat, 1607, p. 253.

Núm. 104. "Mirando estaba Fileno...": el romance puede verse ahora en los Cancionerillos de Munich, op. cit., núm. 64.

Núm. 118. "Para mí se hicieron cenas...", "Para mí son buenas las cenas..." El texto parodiado en los dos pasajes calderonianos es evidentemente "Para mí se hicieron penas, / para mí, / para mí que las tengo por buenas / y para penar naçi", con que concluye el romance "De los toros del aldea", del ms. 3700 de la B.N.M., f. $108 \mathrm{v}$, que podría ser de Lope (como de él lo publicó W. Crawford en RHi, 19, 1908, p. 462). A su vez, este texto parece elaborado sobre el cantarcillo cuyo comienzo citan Wilson y Sage: "Para mí, para mí son penas, / para mí que vivo en ellas", B.N.P., ms. Esp. 373, f. 138v; Bibl. Real de Madrid, ms. 617, f. 168; cf. Ledesma, Conceptos espirituales, Madrid, 1602, p. 17. La otra versión ("Para mi son penas, madre...") aparece en muchos sitios: B.N.M., ms. 3951, f. 9v, y ms. 3700, f. 12 (Alonso de Salas); Bibl. Naz. de Nápoles, ms. I-E.65, p. 78; Correas, p. 457a; Juan Valladares de Valdelomar, Caballero venturoso, Primera parte (Gallardo, t. 4, col. 897).

Núm. 129. "Mira Nero de Tarpeya...": otra melodía, en la ensalada "El fuego" de Mateo Flecha el viejo (Las ensaladas, ed. H. Anglés, Barcelona, 1955, Música, pp. 71-72).

Núm. 135. "Esclavo soy, pero cúyo..." La versión de Alcázar aparece anónima en el Cancionero sevillano, f. 255v, y en el Cancionero classense, núm. 191. Otras glosas del siglo xvi: Comedia a lo pastoril (ed. W. Crawford, RHi, 24, 1911, p. 525, vs. 956-959); ANdrade CAminha, Poesias inéditas, núm. 419; ms. hispanoportugués de la Academia de la Historia (cf. J. García Soriano, BRAE, 12, 1925, p. 369: "Cautivo soi..."); B.N.M., ms. 3168, f. 21. Hay una contrahechura de Padilla, en su Thesoro, Madrid, 1580, f. 183 ("Si a nadie el Amor 
dio cúyo, / tal como a mí me lo dio, / disparate haría yo / en no decir que soy suyo"). Cf. también la cita y la contrahechura que aparecen en el Cisne de Apolo de Carballo (ed. A. Porqueras Mayo, t. 2, Madrid, 1958, p. 175) y las que trae a cuento MedinA, 1908, p. 194. Lope usó y abusó de la famosa cuarteta; además de las cuatro comedias que mencionan WiLson-SAGE, la incluyen El desdén vengado, II (ed. M. M. Harlan, New York, 1930, p. 61), El rey por semejanza (AcadN, t. 2, p. 518b), El mayor rey de los reyes, III (AcadN, t. 7, p. 457ab) y El negro del mejor amo, II (AcadN, t. 11, p. 89). Cf. J. M. Alín, El cancionero español de tipo tradicional, Madrid, 1968, núm. 557. Todavía entrado el siglo xvn la parodió BELMONTE en el entremés Una rana hace ciento (Flor de entremeses, Madrid, 1903, pp. 183-184).

Núm. 146. "Señor Gómez Arias...": cf. ahora J. B. Avalle-Arce, "El cantar de La niña de Gómez Arias", BHS, 44 (1967) , 43-48.

Núm. 148. "Fuego de Dios en el querer bien..." El romancillo "Yo vi una mozuela" está también en el Cancionero classense, núm. 211; aquí y en el Romancero de Turin el segundo verso es "amén, amén". El texto del $R$. G., núm. 925, figura en el pliego suelto Romance de la bella Celia..., Barcelona, Herederos de Juan Jolis (B.N.P., Rés.Yg. 137). En El poeta castellano Antonio Balvas Barona..., Valladolid, 1627 , f. $74 \mathrm{v}$, se lee el estribillo (con "amén, amén"), intercalado en una ensalada. Cf. Correas, p. 34la: "Fuego malo kon el kerer bien, amén, amén".

Núm. 163. "Tú, que me miras a mí..." Ya en el Cancionero del British Museum $(R F, 10,1899,1-176)$, núm. 245, hay un antecedente de la copla, atribuido a Alvarez Gato: "Tú, que miras todos éstos, / mira, pecador de ti, / que disformes y dispuestos..." Véase también la parodia de Montemayor (Cancionero, Madrid, 1932, p. 37) : "Oh, tú, que miras a mi, / tan triste, raído y feo, / mírate, ropón, a ti, / que qual te viste me vi, / y ve[rá]ste qual me veo".

Núm. 172. "Soñaba yo que tenía..." La famosísima cuarteta aparece glosada además en varios mss. de la B.N.M.: 4117, f. 97, y 3888, f. 279 (misma glosa) ; 3968, f. 177; 4072, f. 4v; en JERónimo DE CovaRRUBiAs, La enamorada Elisea, 1594, f. 228v. Con "Soñaba, madre, que vía...", la glosan Andrade Caminha, Poesias inéditas, núm. 386, y Diogo Bernardes, Rimas varias, op. cit., f. 163v. Para las muchas referencias en Lope de Vega, cf. J. F. Montrsinos, ed. de Barlaain y Josafat, Madrid, 1935, p. 248, nota 1 .

Núm. 173. "Yo, que lo sé, que lo vi, te lo digo..." Además de la versión de LEDESMA", conozco otras tres divinizaciones: VAldivielso, Letrilla a San Juan Bautista, Romancero, Madrid, 1648, f. 22v; Villancicos que cantaron... S[evilla $] . . .1612,4$ hs. (H.S.A.), y Juan RoDRíguez DE ABRIL, Chanzonetas de los maitines... en la Catedral de México (1654; en A. Méndez Plancarte, Poetas novohispanos, t. 2, México, 1944, p. 81).

5 Que no está en los Conceptos espirituales de 1602, sino en la Tercera parte, de 1612 , f. 69 . 
Núm. 175. "... Vaya y venga la tabla al horno..." Cf. Correas, p. 514b: "Vaia i venga la pala al horno, ke nunka la falte pan"; GrróNImo DE Porras, Rimas varias, Antequera, 1639, f. 96: "Que vaya o venga la tabla al horno, / que ya no me falta pan, / que en Belén como unas flores / de balde a todos se da". Cf. también el Entremés del Emperador, en Teatro poético repartido en veintiún entremeses nuevos, Zaragoza, 1658, pp. 150-15l: “...que vaya y venga, todo ruede, / como a mí no me haga mal", y la parodia de Quiñones de Benavente, El mago (Cotarelo, Entremeses, t. 2, p. $581 b$ ): “-Que vaya y venga al Retiro el baile..."

El Colegio de México.

Margit Frenk Alatorre

\section{SOBRE EL TEXTO ORIGINAL DE LAS RIMAS DE BÉCQUER (A PROPÓSITO DE LA EDICIÓN DE J. P. DIAZ)}

Muchos años después de las poesías de Quintana, de Zorrilla y del $P$. Arolas, las Rimas de Bécquer han entrado por fin, al cuidado de José Pedro Díaz, uno de los mejores conocedores actuales del poeta andaluz, en la popular y benemérita colección de Clásicos castellanos ${ }^{1}$. El tomito, de impresión aireada y limpia, es muy agradable. La amplia introducción, en que el editor, resumiendo sus investigaciones previas ${ }^{2}$, estudia la vida (pp. x-lvii) y la poesía (pp. lvii-cx) de Bécquer, está excelentemente hecha y no deja sin tocar ningún aspecto importante.

En las últimas páginas (cx-cxix) de la introducción expone Díaz el criterio de su edición. Los razonamientos que hace y las conclusiones a que llega se traducen, en el cuerpo del volumen, en un texto de las Rimas que no se parece al de ninguna de las ediciones anteriores. Resultado, pues, nada trivial, y que ya por sí merece atención. Ahora bien, este texto me parece incorrecto. Y como lo que está en juego es la autenticidad de la expresión de un poeta muy querido, no creo que esté por demás considerar el problema con algún detenimiento.

Como se sabe, el único texto de las Rimas que se leyó durante casi medio siglo, desde la muerte del poeta hasta 1914, es el que imprimieron las sucesivas ediciones de Obras de Bécquer, a partir de la primera -póstuma-, impresa en Madrid por Fortanet en 1871. Pero en 1914 se publicó en Leipzig la tesis doctoral de Franz Schneider, Gustavo Adolfo Bécquers Leben und Schaffen, que reveló la existencia del Libro de los gorriones, manuscrito autógrafo de las Rimas, fechado en 1868. Después de la primera Guerra mundial, Schneider volvió a describir ese autógrafo en $M P h, 19$ (1921-22), 245-256. El hispanista alemán encontró: 1) que el orden en que aparecían las poesías en el ms. original era completamente distinto del que mostraban los impresos; 2) que en el Libro de los gorriones figuraban tres poesías no incluidas en las

1 Béceuer, Rimas. Ed., introd. y notas de José Pedro Díaz, Espasa-Calpe, Madrid, 1963; cxix + 148 pp. (Clás. cast., 158).

2 José Pedro DíAz, Gustavo Adolfo Bécquer, Vida y poesia, Montevideo, 1953, y ediciones posteriores en la $B R H$ de Gredos, Madrid. 